\title{
Independently Rotating Wheels with Induction Motors for High-Speed Trains
}

\author{
B. Liang and S. D. Iwnicki \\ Department of Engineering and Technology, Manchester Metropolitan University, Manchester M1 5GD, UK \\ Correspondence should be addressed to B. Liang, b.liang@mmu.ac.uk
}

Received 22 September 2010; Accepted 22 February 2011

Academic Editor: Ian R. Petersen

Copyright (๑) 2011 B. Liang and S. D. Iwnicki. This is an open access article distributed under the Creative Commons Attribution License, which permits unrestricted use, distribution, and reproduction in any medium, provided the original work is properly cited.

\begin{abstract}
Railway vehicles with conventional wheelsets often experience problems of lateral instabilities or severe wear when running at high speed. The use of an independently rotating wheelset (IRW) can potentially eliminate the cause of wheelset hunting and reduce wheel wear as the mechanical feedback mechanism causing the problem is decoupled. This paper presents an investigation into the design of a novel induction motor configuration and controller for IRW in order to provide the stability required to satisfy the performance requirements for railway vehicles. A computer model of the mechanical and electrical parts of the system was developed. Simulation and experiments of the wheelsets with active driving motor control have demonstrated that a wheelset with independently driven wheels has a good stability performance over a traditional wheelset. Controllers with indirect field orientation control for dynamic control of an induction motor have shown to be suitable for this application in both its response and its controllability.
\end{abstract}

\section{Introduction}

It is well known that railway vehicles with conventional wheel sets experience problems of hunting and severe wear. The use of independent wheels could eliminate the cause of wheelset hunting and reduce the wheel wear since IRW can decouple the wheels. The IRW for railway vehicles has been under serious consideration at a theoretical and experimental level for thirty years. However, the use of IRW would also eliminate the guidance capability of the railway vehicles. A compromise could be achieved between the excellent stability behaviour of IRW and the guidance capability by use of active controls like yaw control, creep control or damping, and stiff control. Much effort has been directed to the solution of this problem. For example, independent wheels with profiled treads, independent wheels with partial coupling, or with a superimposition gearbox have been proposed by Kaplan [1], Dukkipati [2], and Jaschinski [3], respectively. Alternatively separate drive motors with precise torque control can be used to provide guidance and curving capability (Gretzschel [4]). Professor Goodall investigated active steering and optimized control strategy for independently rotating wheels [5-7].
Although some good computer simulation results have been achieved, the experimental validations have not been done yet. This paper presents not only a successful dynamic control simulations for independently rotating wheels but also validates all simulation results by a new designed test rig. There are two distinguished aspects with this research. Firstly, instead of adopting very complex and impractical sensor feedback systems, a simple but effective yaw feedback control mechanism was implemented. It could significantly reduce the control complexity for independently rotating wheelsets. Secondly, the independent wheels were driven by induction motors which are more reliable, more powerful, cost effective and small in size compared to conventional dc motors. The controller adopts a modern vector control strategy to control the driving motors and a real-time profibus-based control system has been designed. In Sections 2 and 3 the mechanical and electric models of the IRW are presented. Then, in Section 4, the implementation of the modelling by Matlab/Simulink is given. The actual design of the test rig and corresponding-real time profibus control system are described in Section 5. Finally Sections 6 and 7 discuss and give some simulation and experimental results. 


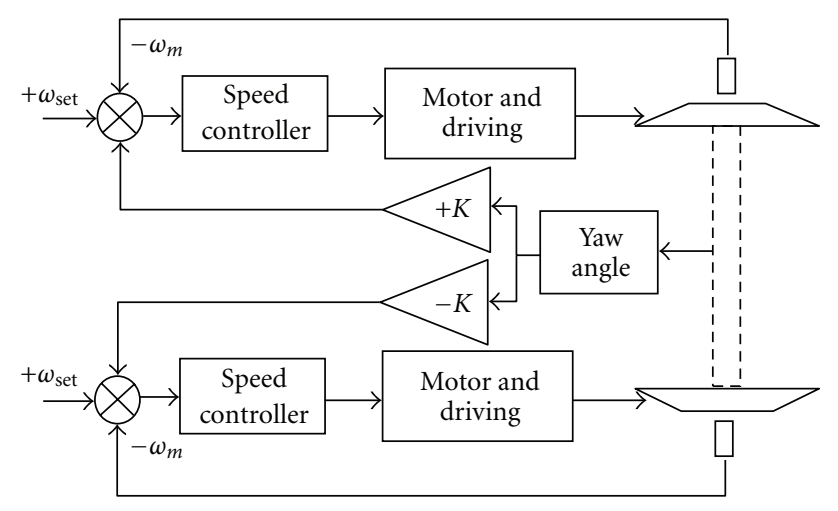

FIGURE 1: The overall control strategy.

\section{Wheelset and Induction Modelling}

2.1. Wheelset Modelling. A wheelset is an important dynamic component of a railway vehicle. Generally speaking, the following equations are linear approximations for the motion of a solid axle wheelset [8]. The wheelset is taken as having the two degrees of freedom of lateral translation motion and yaw rotation.

$$
\begin{gathered}
m \ddot{y}+2 f_{22}\left(\frac{\dot{y}}{v}-\psi\right)-F_{y}-\frac{m v^{2}}{R_{0}}-m g \vartheta=0, \\
J_{w} \ddot{\psi}-2 f_{22}\left(\frac{\dot{y}}{v}-\psi\right)+2 f_{33} \frac{\psi}{v}+2 f_{11}\left(\frac{l_{0}^{2} \dot{\psi}}{v}+\frac{l_{0} \lambda y}{r_{0}}\right)=0 .
\end{gathered}
$$

The equations for IRW are very similar to the conventional solid axle wheelset in additional to the introducing of one more state $\theta$, which is the differential angle of rotation of wheels. The IRW models can be given as follows:

$$
\begin{gathered}
m \ddot{y}+2 f_{22}\left(\frac{\dot{y}}{v}-\psi\right)-\frac{m v^{2}}{R_{0}}-m g \vartheta-F_{y}=0, \\
J_{w} \ddot{\psi}+2 f_{11}\left(\frac{l_{0}^{2} \dot{\psi}}{v}+\frac{l_{0} \lambda y}{r_{0}}+\frac{l_{0} r_{0}}{v} \dot{\theta}+\frac{l_{0}^{2}}{R_{0}}\right)-T_{w}=0, \\
J_{\theta} \ddot{\theta}-f_{11}\left(\lambda y-\frac{l_{0} r_{0}}{v} \dot{\psi}-\frac{r_{0}^{2}}{v} \dot{\theta}-\frac{l_{0} r_{0}}{R_{0}}\right)=0 .
\end{gathered}
$$

The above set of equations describes the behaviour of a complete wheelset.

2.2. Driving Induction Motor Modelling. With the availability of faster and less expensive processors and solidstate switches, AC induction motor drives now compare favourably to DC motor drives in the aspects of power to weight ratio, acceleration performance, control flexibility, and maintenance. We adopted induction motors as driven power. Every independently rotating wheel was designed by an independent induction motor (Figure 1). The independent induction motors at each wheel will provide the required traction and braking efforts. With this arrangement the torque at each wheel can be controlled to generate axle yaw and, therefore, steering guidance. This is mechanically simpler than a superimposition gearbox. Modern vector control techniques have been used to control the induction motors.

The vector control structures are based on flux vector determination of induction motors. There are two basic vector control structures. The first is flux measurement or sensing which is known as a direct field-oriented controlled drive. The second is based on flux modelling or slip relationship, and this method is known as an indirect fieldoriented controlled drive. Since the direct field-oriented controlled drive relies on integration that has a tendency to drift, the indirect field oriented controlled drive has been adopted for this application.

It is well known that a general $d, q$ induction motor model with the reference axes rotating at synchronous speed $\omega_{e}$ can be expressed as [9]

$$
\begin{aligned}
V_{q s}^{e} & =R_{s} I_{q s}^{e}+p \phi_{q s}^{e}+\omega_{e} \phi_{d s}^{e}, \\
V_{d s}^{e} & =R_{s} I_{d s}^{e}+p \phi_{d s}^{e}-\omega_{e} \phi_{q s}^{e}, \\
0 & =R_{r} I_{q r}^{e}+p \phi_{q r}^{e}+\left(\omega_{e}-\omega_{r}\right) \phi_{d r}^{e}, \\
0 & =R_{r} I_{d r}^{e}+p \phi_{d r}^{e}-\left(\omega_{e}-\omega_{r}\right) \phi_{q r}^{e}, \\
\phi_{d s}^{e} & =L_{s} I_{d s}^{e}+L_{m}\left(I_{d s}^{s}+I_{d r}^{e}\right), \\
\phi_{q s}^{e} & =L_{s} I_{q s}^{e}+L_{m}\left(I_{q s}^{s}+I_{q r}^{e}\right), \\
\phi_{d r}^{e} & =L_{r} I_{d r}^{e}+L_{m}\left(I_{d s}^{s}+I_{d r}^{e}\right), \\
\phi_{q r}^{e} & =L_{r} I_{q r}^{e}+L_{m}\left(I_{q s}^{s}+I_{q r}^{e}\right), \\
T_{e} & =\frac{3 P L_{m}}{4 L_{r}}\left(\phi_{d r}^{e} I_{q s}^{e}-\phi_{q r}^{e} I_{d s}^{e}\right) .
\end{aligned}
$$

If we let $\phi_{q r}^{e}=0$, this express the field orientation concept in $d, q$ variables. The following expression for the electromagnetic torque, $T_{e}=\left(3 P L_{m} / 4 L_{r}\right)\left(\phi_{d r}^{e} I_{q s}^{e}\right)$, shows that if the rotor flux linkage $\phi_{d r}^{e}$ is not disturbed, the electromagnetic torque can be independently controlled by adjusting the stator $q$ component $I_{q s}^{e}$.

Indirect field orientation is based on the slip relation $\omega_{e}-$ $\omega_{r}=R_{r} I_{q s}^{e} / L_{r} I_{d s}^{e}$. If the above condition is satisfied, it ensures that an AC motor can be controlled in the same manner as a DC motor. This approach is simple and well performing for the speed and position control even at low speeds. However, the major drawback is that the orientation of the control is very sensitive to the rotor resistance, which affects the robustness of the control. To overcome this problem, the rotor resistance has to be estimated online. The detailed configuration for driving the induction motors and inverters is shown in Figure 2. In order to compensate for the flux disturbance which may slightly alter the electromagnetic torque under transient conditions, a torque controller is introduced into the control loop. In the research, the wheelset is assumed to be running only on the straight track. Figure 1 shows that the yaw rotation of the wheelset is used as 


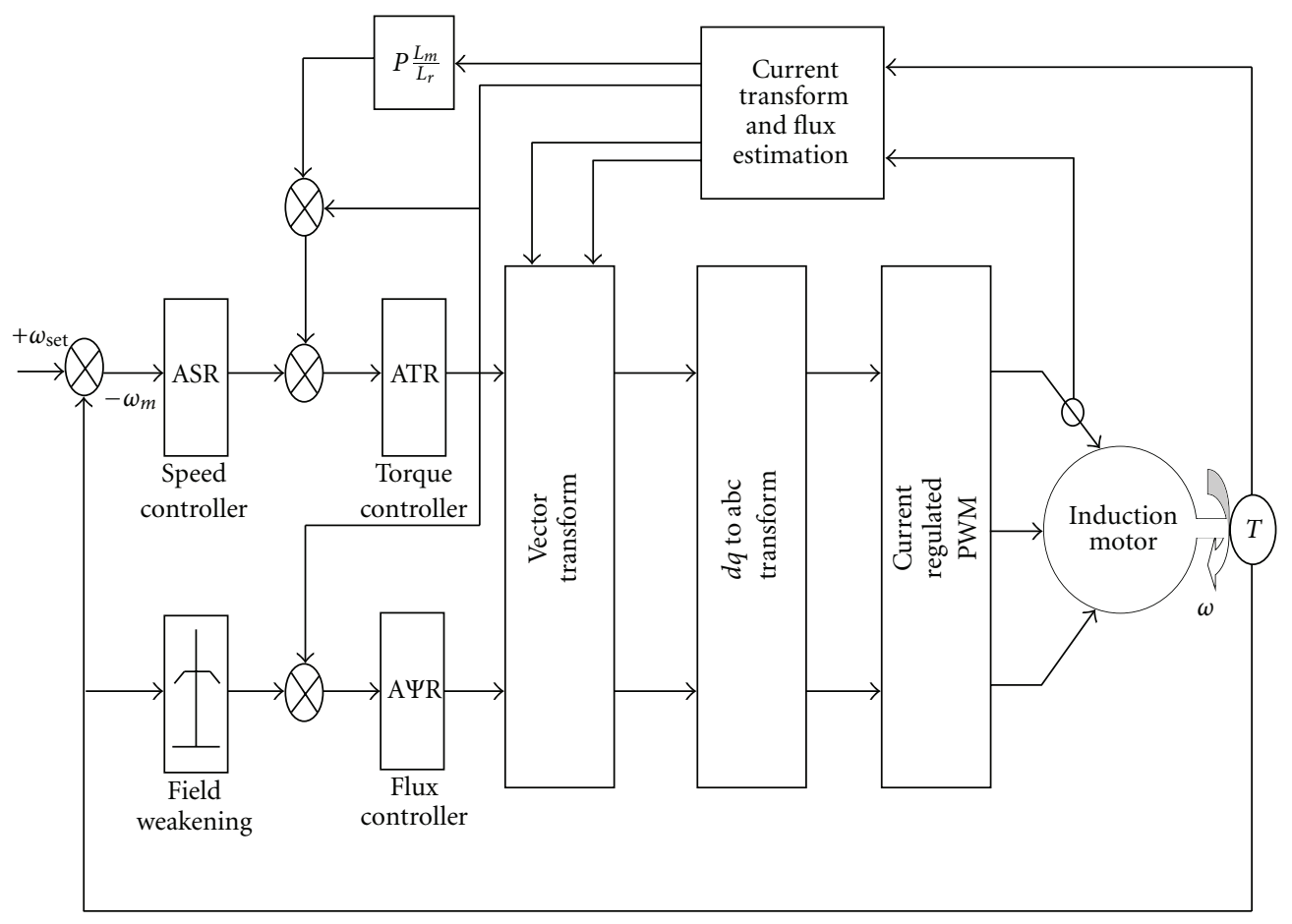

FIGURE 2: The vector control system for driving motor.

an input variable to control the speed difference between the left and right wheels. The implemented whole system block diagram with Matlab Simulink is shown in Figure 3.

\section{The Test Rig Development}

In order to validate the simulation results, a wheelset test rig has been built. The test rig consists of $1 / 5$ scale wheelset, two $1.1 \mathrm{~kW}$ induction motors with 7200 pulse/rev encoders which makes accurate angular synchronism possible, two $1.5 \mathrm{~kW} 6$ SE70 Siemens inverters, corresponding data acquisition systems, and main control computer. The whole configuration was already shown in Figure 1. It can be seen that the driving induction motors can either be independently controlled by the inverters or jointly controlled by the inverters and the main computer. This configuration will give the maximum flexibility and accuracy in controlling the induction motors. The trends today in automation technology are modular, reconfigure, fast, and distributed intelligence. Therefore, the profibus was adopted in this application. The advantages of profibus are open, vender independent protocol, up to $12 \mathrm{Mbaud}$, cost effective solution, and powerful diagnostic capability. The computer interface was designed and implemented by Labwindows software. The wheelset with inverters is given in Figure 4.

\section{Simulation and Experimental Results}

The corresponding mechanical and electrical models have been implemented and simulated by Matlab Simulink soft-
TABLE 1: Model parameters.

\begin{tabular}{lc}
\hline$f_{11}=f_{22}=800000 \mathrm{~N}$ & $f_{33}=60000 \mathrm{~N}$ \\
\hline$f_{33}=12.5 \mathrm{Nm}^{2}$ & $J_{\mathrm{w}}=1.8 \mathrm{Kgm}^{2}$ \\
$J_{\theta}=0.4 \mathrm{Kgm}^{2}$ & $L_{\mathrm{s}}=0.046 \mathrm{H}$ \\
$L_{\mathrm{r}}=0.042 \mathrm{H}$ & $L_{\mathrm{m}}=0.042 \mathrm{H}$ \\
$l_{0}=0.143 \mathrm{~m}$ & $m=18.6 \mathrm{Kg}$ \\
$R_{\mathrm{s}}=2.3 \Omega$ & $R_{\mathrm{r}}=1.2 \Omega$ \\
$r_{0}=0.1 \mathrm{~m}$ & $\lambda=0.15$ \\
$P=2$ & \\
\hline
\end{tabular}

ware. Table 1 presents the corresponding parameters of models used for simulations.

The fundamental idea of the IRW with yaw feedback controller is to use speed difference between left and right wheels to control the yaw movement and lateral displacement of the wheelset. The improved stability behaviour of the IRW can be determined by observing whether the response of the wheelset to an initial lateral disturbance. Figure 5 gives one the simulation results for a wheelset without wheel motor driving control subjected to a $5 \mathrm{~mm}$ lateral pulse disturbance at $30 \mathrm{~m} / \mathrm{s}$ running speed. It can be seen that the lateral oscillation and yaw movement of the wheelset started to oscillate after a $5 \mathrm{~mm}$ lateral disturbance was given. Both oscillation amplitudes of lateral movement and yaw movement increased with time. The lateral and yaw oscillating frequency is about $2.8 \mathrm{~Hz}$. Figure 6 shows the corresponding simulation results under the same conditions 


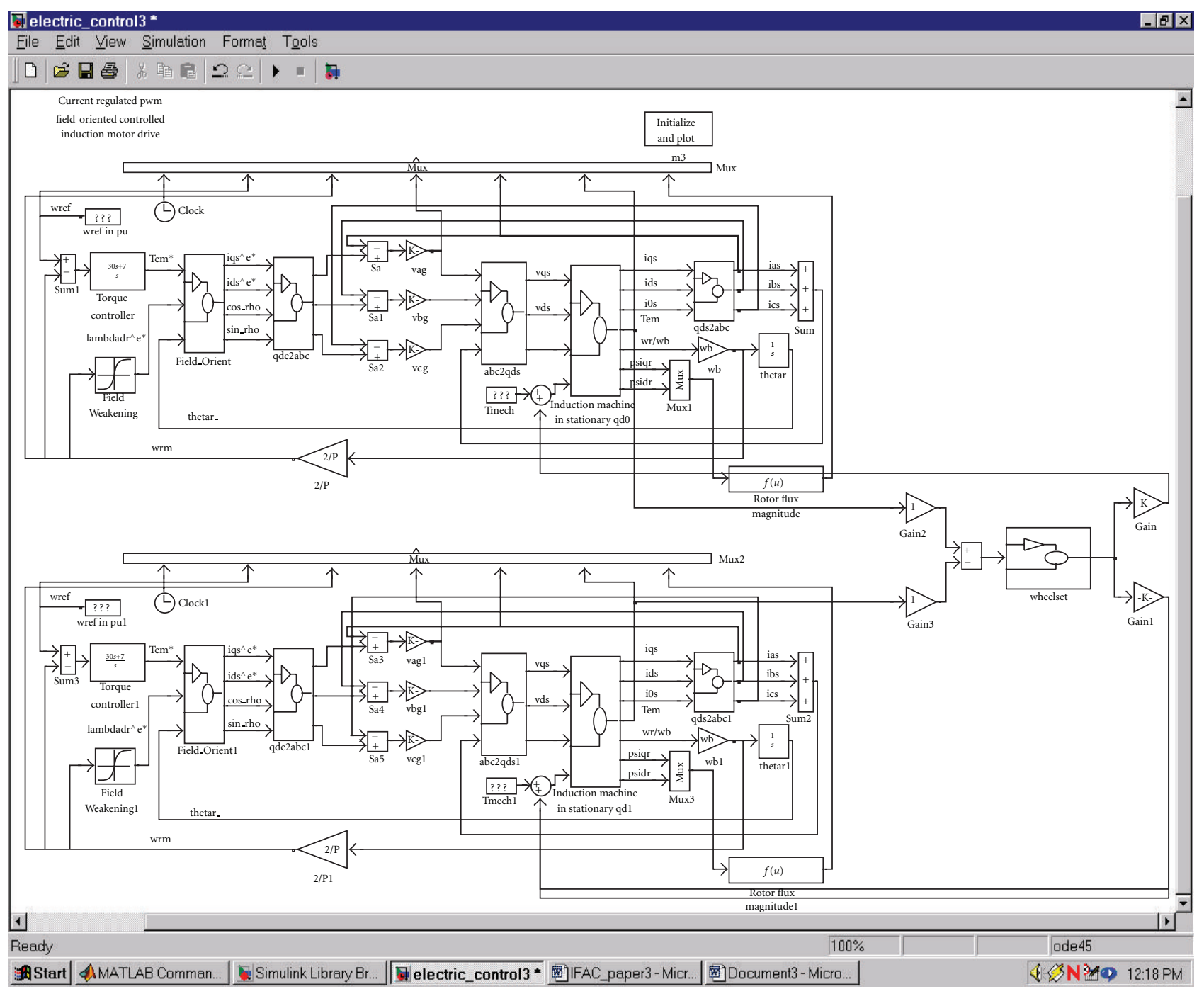

Figure 3: The simulink block diagram of the whole system.

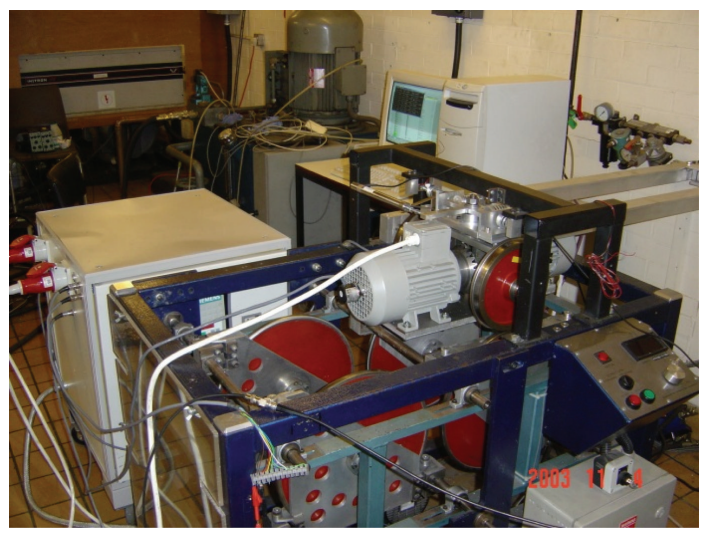

FIgURE 4: The wheelset and test rig.

but with active driving motor control. It clearly indicates that the lateral ripple and yaw oscillation will die out very quickly after the disturbance. Figures 7 and 8 present another pair of simulations without and with active motor driving control but at $50 \mathrm{~m} / \mathrm{s}$ running speed. It can be seen that much higher oscillations for the lateral and yaw movement occurred if without active driving control after the $5 \mathrm{~mm}$ disturbance was introduced. However, the ripples of lateral and yaw movements would be under control very quickly if active driving control was applied.

\section{Assessment of Results}

A comparison between simulated and measured speeds for a wheel motor in free running is shown in Figure 9. It can be seen that a good agreement for its running speed and torque between simulations and experimental results is achieved.

Figure 10 shows the measured yaw movements of the IRW with and without yaw feedback control at about $30 \mathrm{~m} / \mathrm{s}$ running speed. In Figure 10, it is seen that the IRW with yaw feedback control gives much better performance than 

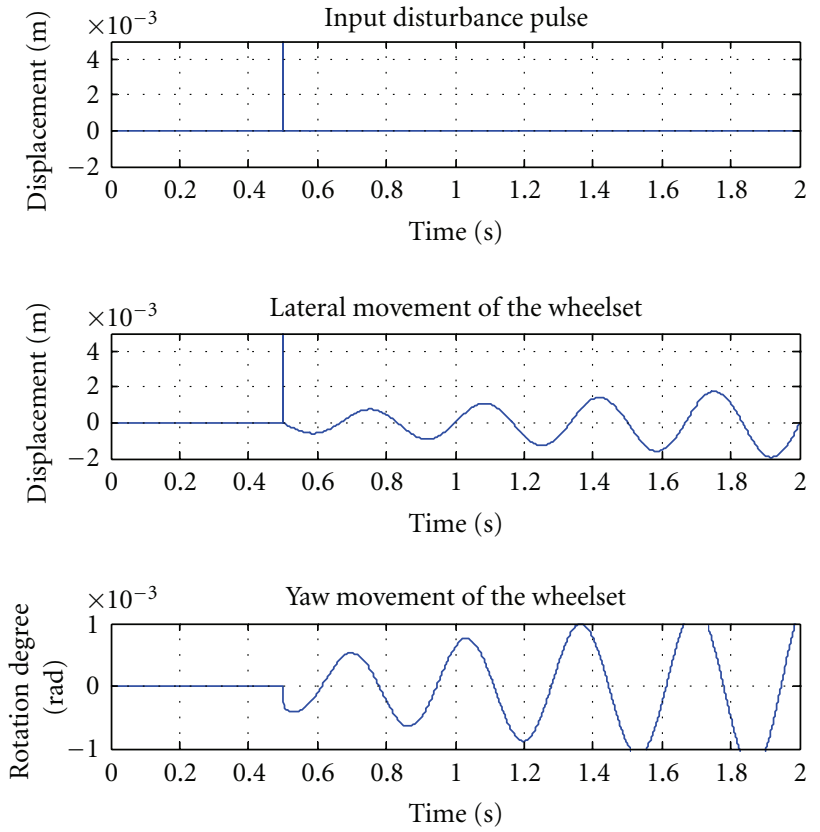

FIgURE 5: A wheelset without active motor control at $30 \mathrm{~m} / \mathrm{s}$ running speed.
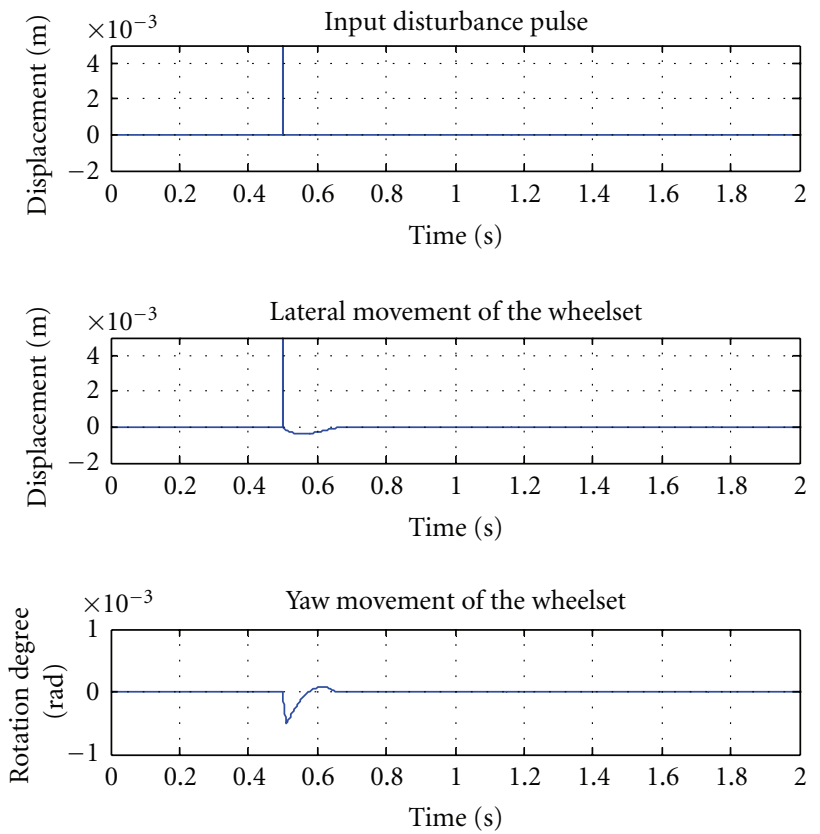

FIGURE 6: A wheelset with active motor control at $30 \mathrm{~m} / \mathrm{s}$ running speed.

IRW without yaw feedback control. The yaw movement of the IRW with yaw feedback control is barely visible while the IRW without yaw feedback control starts to show oscillation after a disturbance. The oscillation frequency is about $2.8 \mathrm{~Hz}$ which shows the good agreement with the computer simulation result presented in Figure 5.
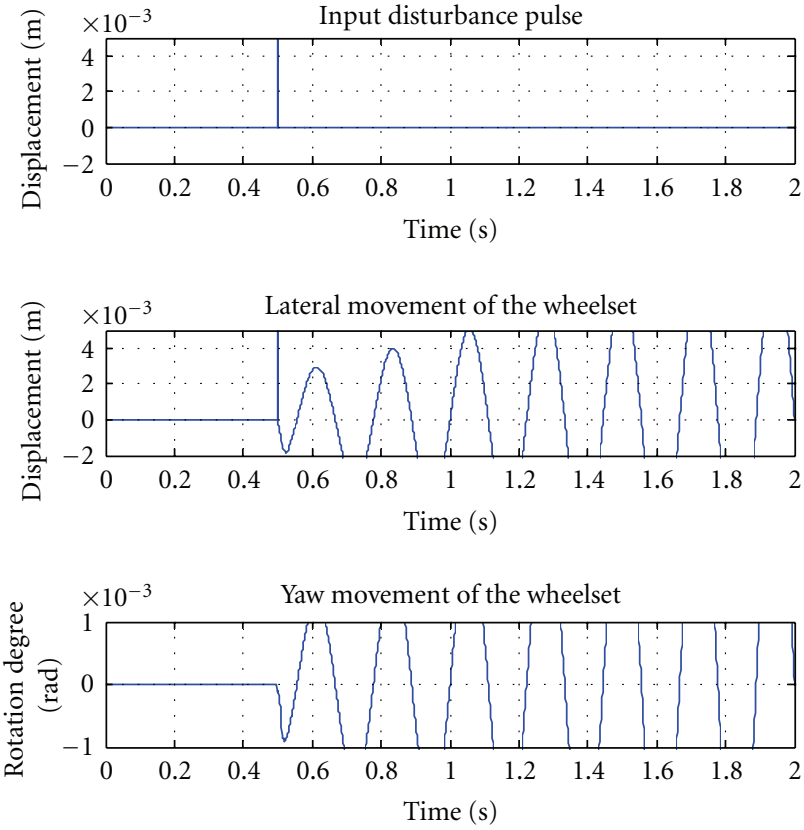

FIGURE 7: A wheelset without active motor control at $50 \mathrm{~m} / \mathrm{s}$ running speed.
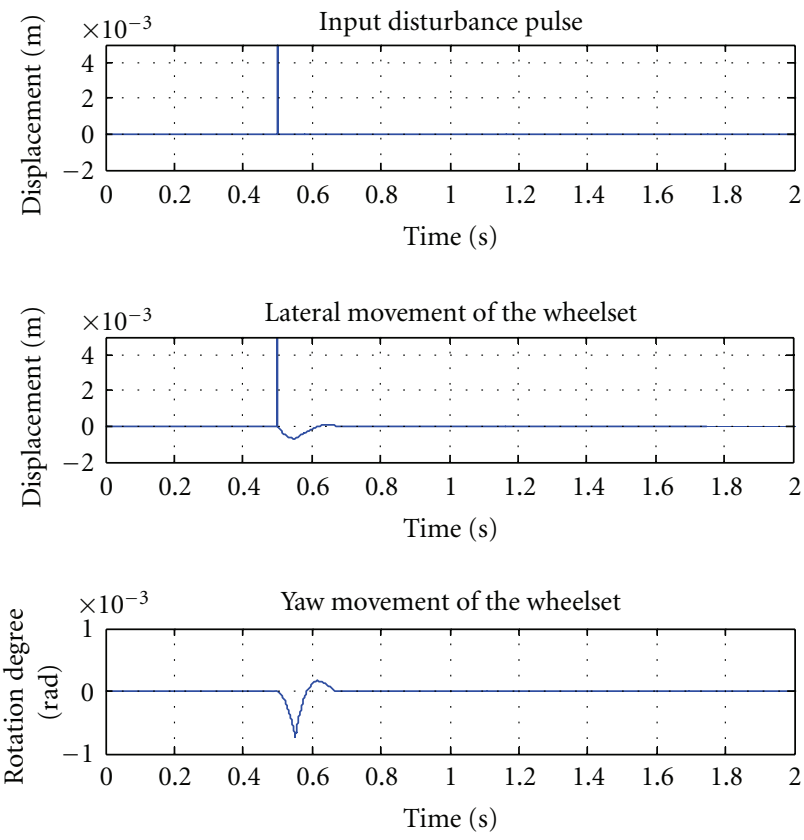

FIGURE 8: A wheelset with active motor control at $50 \mathrm{~m} / \mathrm{s}$ running speed.

Figures 11 and 12 present the wheel motor speed fluctuations under with and without yaw feedback controls. The lower parts of the two figures are the corresponding wheel speed variations after a filter. It is indicated again that the IRW with yaw feedback provides good stable capability. The $1 / 5$ scale test rig has been tested and able to run up to 

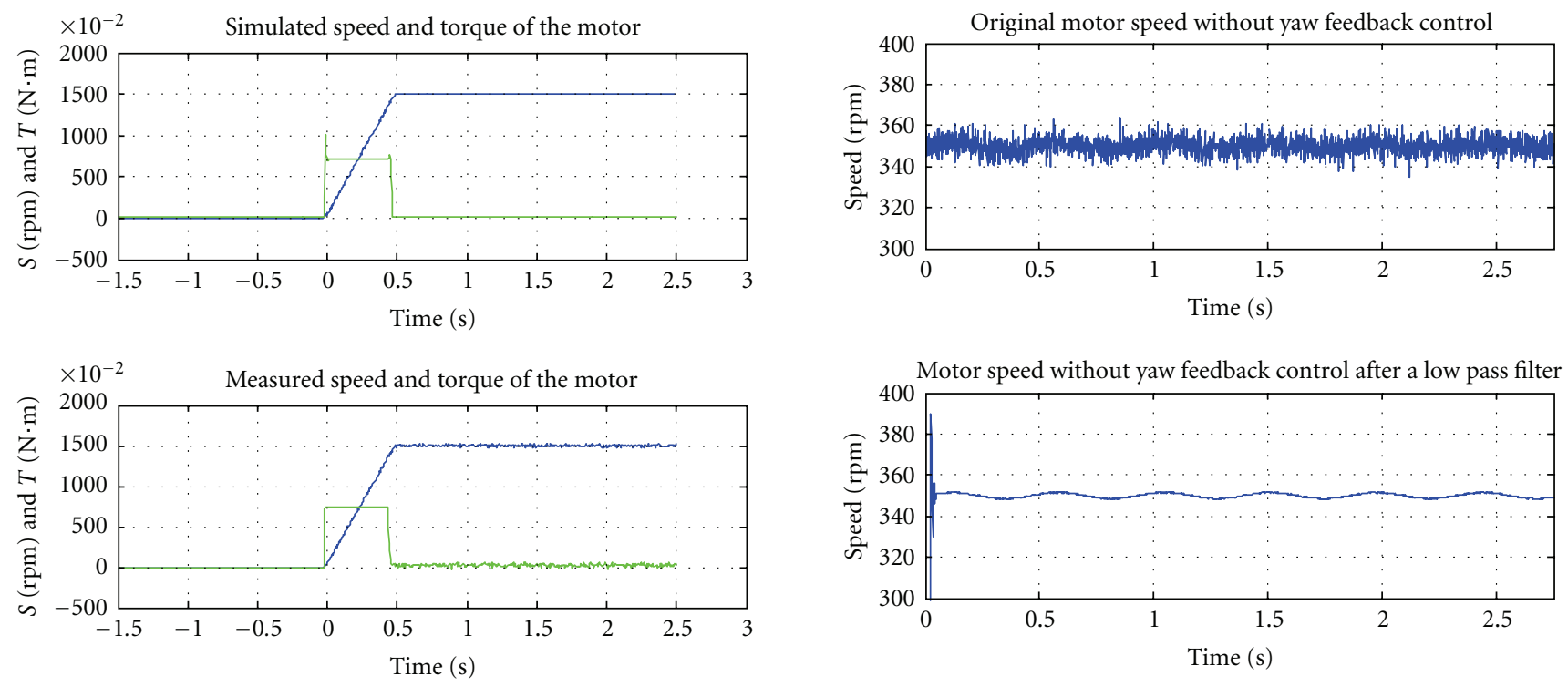

FIGURE 9: A comparison between simulated and experimental results for a free running wheel motor.
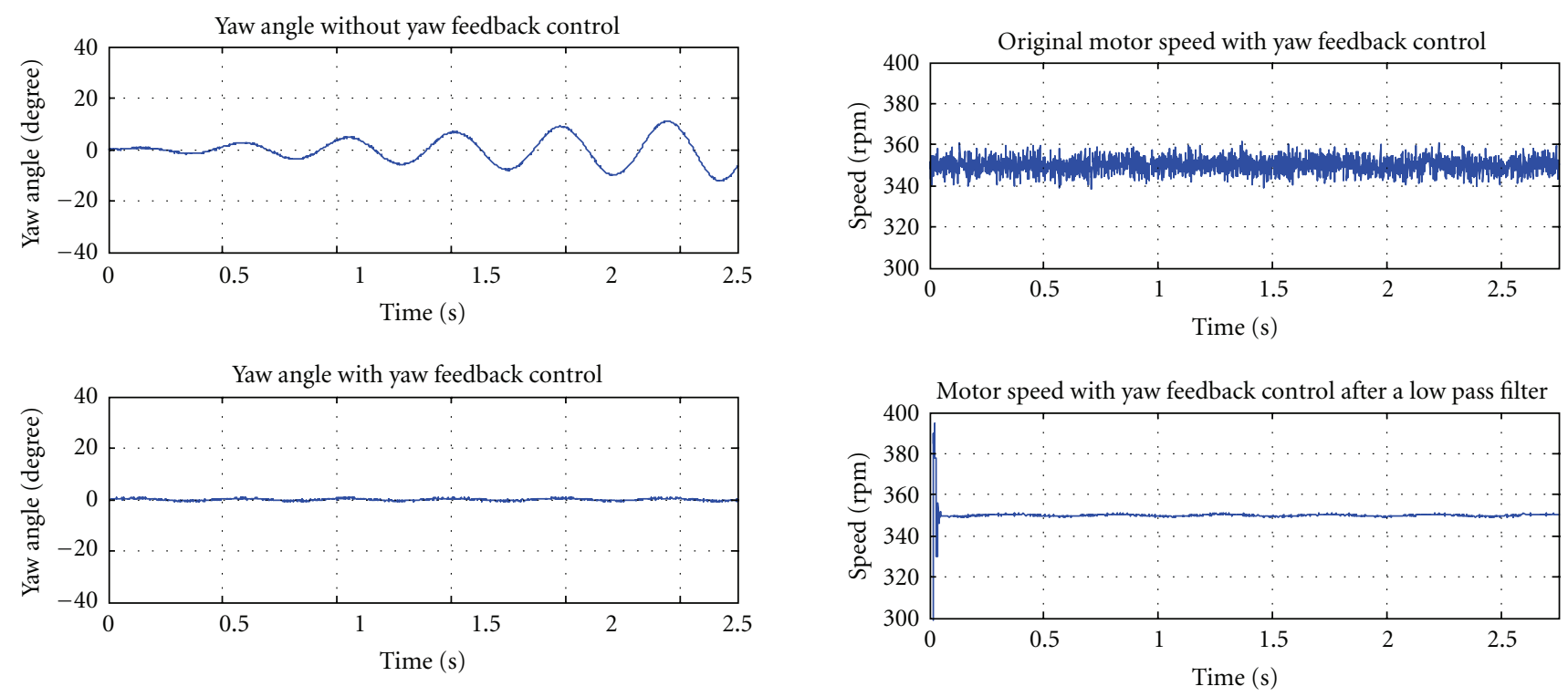

FIGURE 10: The measured yaw movement without and with yaw feedback control.

maximum $60 \mathrm{mph}$ (which equals to $300 \mathrm{mph}$ in real size) while holding good stable capability.

\section{Conclusions}

In this paper, a wheelset with independently rotating wheels with actively controlled driving motors has been modelled, implemented, and validated by an experimental test rig. The findings can be summarized as follow.

(1) Indirect field orientation control for dynamic control of motor has been shown to be suitable for this application in both its response and its controllability.

FIgure 11: The measured wheel speed without yaw feedback control.

FIGURE 12: The measured wheel speed with yaw feedback control.

(2) The yaw feedback control alone could provide some kind of guidance which is lost by independently rotating wheels arrangement. The simulation of a wheelset with independently rotating wheels and active driving motor control has demonstrated a better stability performance over a traditional wheelset.

(3) The simulation results have been validated, and experimental results have shown that the proposed configuration and control methodology could lead to improved stability and good steering for a railway wheelset. 


\section{Nomenclature}

$\begin{array}{ll}f_{11}, f_{22}, f_{23}, f_{33}: & \text { Creep coefficients } \\ F_{y}: & \text { Lateral force } \\ I_{d s}^{e}, I_{q s}^{e}, I_{d r}^{e}, I_{d r}^{e}: & d, q \text { currents of stator and rotor } \\ J_{w}: & \text { Wheelset yaw inertia } \\ J_{\theta}: & \text { Wheel inertia } \\ +K,-K: & \text { Coefficients } \\ L_{s}, L_{r}, L_{m}: & \text { Self- and mutual inductances of } \\ & \text { stator and rotor } \\ l_{0}: & \text { Semigauge } \\ m: & \text { Wheelset mass } \\ P: & \text { Pole pairs of motor } \\ p: & \text { Differential operator } \\ R_{0}: & \text { Curve radius } \\ R_{s}, R_{r}: & \text { Resistances of stator and rotor } \\ r_{0}: & \text { Wheel radius } \\ T_{e}: & \text { Electromagnetic torque } \\ T_{w}: & \text { Yaw torque } \\ V_{d s}^{e}, V_{q s}^{e}: & d, q \text { voltage of stator } \\ v: & \text { Wheelset forward speed } \\ y: & \text { Lateral movement } \\ \lambda: & \text { Conicity } \\ \phi_{d s}^{e}, \phi_{q s}^{e}, \phi_{d r}^{e}, \phi_{d r}^{e}: & d, q \text { fluxes of stator and rotor } \\ \theta: & \text { Differential angle of rotation of } \\ \vartheta: & \text { wheels } \\ \psi: & \text { Track cant } \\ \omega_{e}, \omega_{r}: & \text { Wheelset yaw movement } \\ & \text { Synchronous and rotor speed of } \\ & \text { motor. }\end{array}$

\section{References}

[1] A. Kaplan, T. K. Hasselman, and S. A. Short, "Independently rotating wheels for high speed trains," SAE Paper 700841, 1970.

[2] R. V. Dukkipati, "Dynamics of independently rotating wheelsets-A survey of the state of the art," Tech. Rep. LTR-IN398, NRC Railway Laboratory, 1978.

[3] A. Jaschinski, H. Chollet, S. Iwnicki, A. Wickens, and J. Von Würzen, "The application of roller rigs to railway vehicle dynamics," Vehicle System Dynamics, vol. 31, no. 5-6, pp. 345392, 1999.

[4] M Gretzschel and L. Bose, "A new concept for integrated guidance and drive of railway running gears," in Proceedings of the 1st IFAC Conference on Mechatronic Systems, vol. 1, pp. 265270, Darmstalt, Germany, 2002.

[5] R. Goodall and T. X. Mei, "Mechatronic strategies for controlling railway wheelsets with independently rotating wheels," in Proceedings of the IEEE/ASME International Conference on Advanced Intelligent Mechatronicsn (AIM '05), vol. 1, pp. 225230, Como, Italy, 2005.

[6] T. X. Mei and R. M. Goodall, "Robust control for independently rotating wheelsets on a railway vehicle using practical sensors," IEEE Transactions on Control Systems Technology, vol. 9, no. 4, pp. 599-607, 2001.

[7] T. X. Mei and R. M. Goodall, "Practical strategies for controlling railway wheelsets independently rotating wheels," Journal of
Dynamic Systems, Measurement and Control, Transactions of the ASME, vol. 125, no. 3, pp. 354-360, 2003.

[8] V. K. Grag and R. V. Dukkipati, Dynamics of Railway Vehicle Systems, Academic Press, London, UK, 1984.

[9] D. W. Novotny and T. Lipo, A Vector Control and Dynamics of AC Drives, Clarendon Press, Oxford, UK, 1996. 

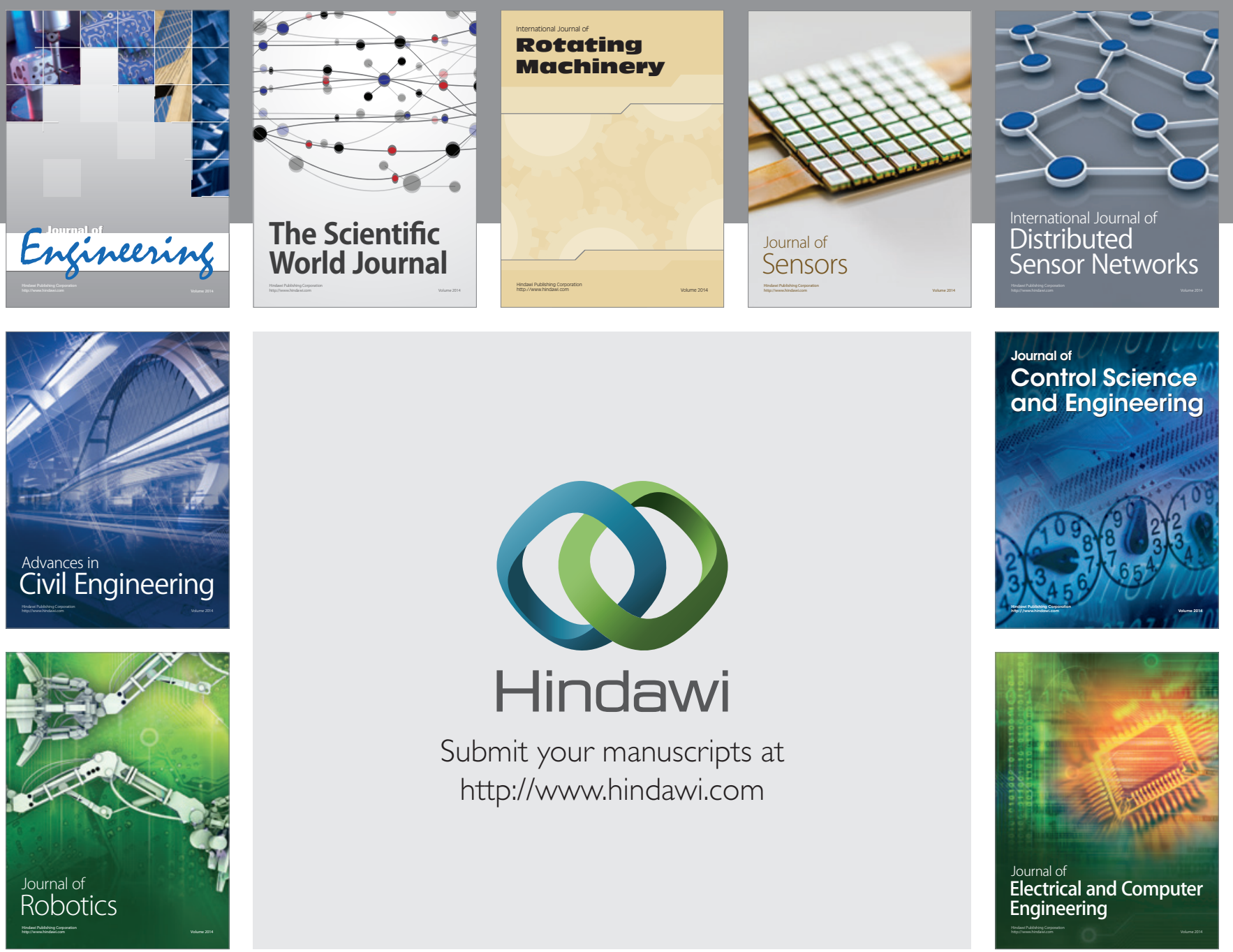

Submit your manuscripts at

http://www.hindawi.com
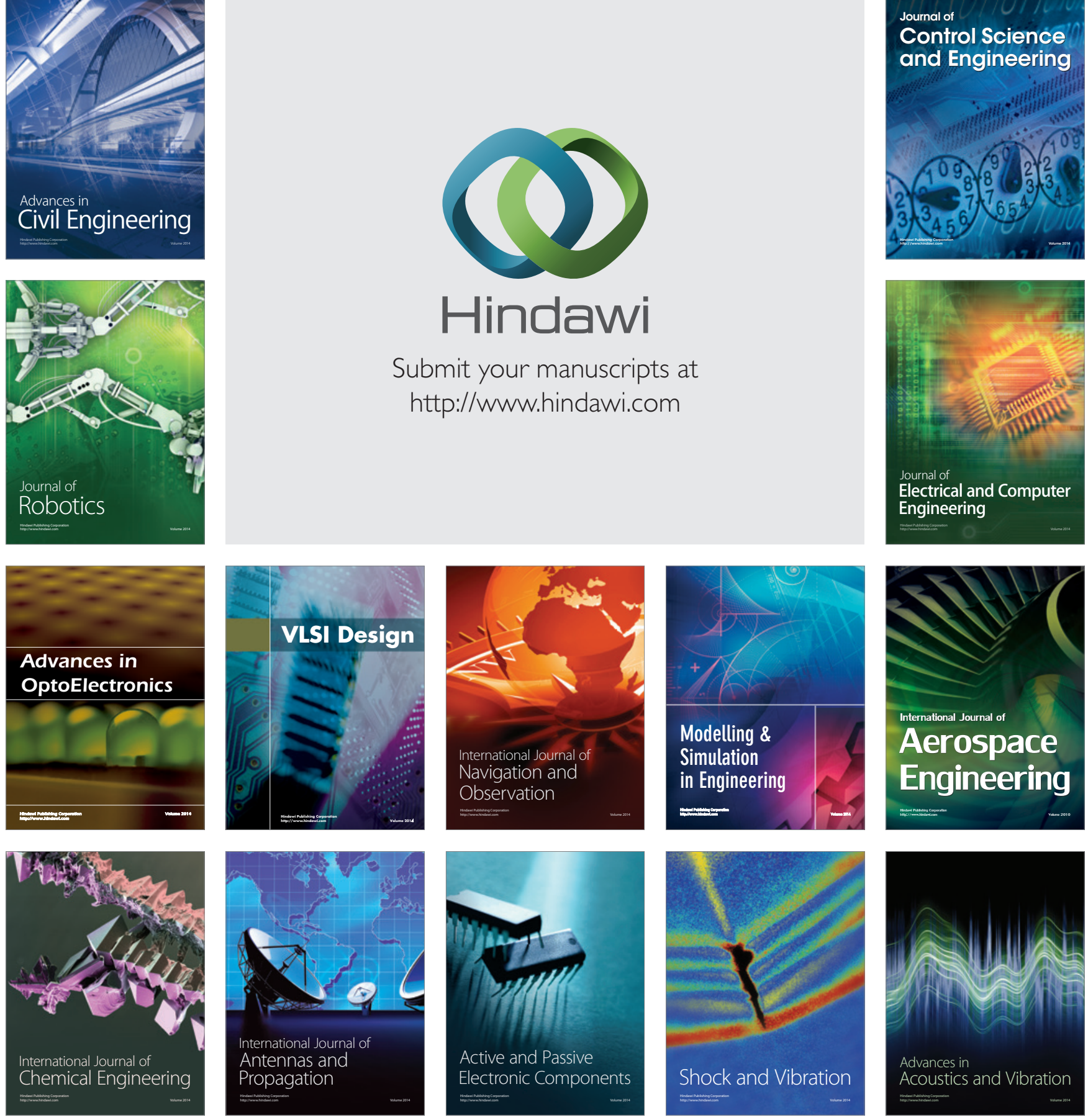